\title{
Jurnal Einstein
}

\section{Analisis Sifat Mekanis Dan Struktur Nanokomposit Abu Sekam Padi Sebagai Filler Termoplastik Hdpe}

\author{
Eva Marlina Ginting dan Martha Marchofinece Padang*
}

Jurusan Fisika, Fakultas Matematika dan Ilmu Pengetahuan Alam, Universitas

Negeri Medan, Indonesia

Diterima April 2016; Disetujui Mei 2016; Dipublikasikan Juni 2016

\begin{abstract}
Abstrak
Telah dilakukan penelitian pengolahan dan karakterisasi abu sekam padi sebagai bahan pengisi termoplastik HDPE. Penelitian ini dilakukan untuk mengetahui pengaruh pengisi terhadap kekuatan mekanis nanokomposit serta bagaimana struktur permukaan nanokomposit.Nanopartikel abu sekam padi telah berhasil disintesis dengan metode kopresitasi dengan menggunakan PEG 6000 sebagai template nanopartikel, sehingga dipergunakan perbandingan 1:3 antara nanopartikel dengan PEG. Penggunaan nanopartikel abu sekam padi sebagai bahan pengisi termoplastik HDPE dilakukan dengan menggunakan kompatibiliser Pe-g-MA menjadi nanokomposit.Dari hasil uji tarik dihasilkan bahwa nanokomposit HDPE/ASP dengan menggunakan kompatibiliser Pe-g-MA hasil uji tarik nanokomposit menghasilkan sampel dengan nilai terbaik yaitu pada komposisi pengisi yang masing-masing untuk HDPE/Pe-g-MA/ASP dengan kekuatan tarik $20.60133 \mathrm{MPa}$ (pengisi $2 \%$ ), modulus Young's sebesar 619.7633 MPa (pengisi $10 \%$ ), tegangan putus sebesar $15.737 \mathrm{MPa}$ (pengisi $4 \%$ ), dan regangan putus sebesar 591.5333\% GL (pengisi $8 \%$ ).
\end{abstract}

Kata kunci : HDPE, nanopartikel, abu sekam padi, PE-g-MA, analisis SEM, analisis mekanis.

How to Cite: Eva Marlina Ginting, Martha Marchofinece Padang, (2016), Analisis Sifat Mekanis Dan Struktur Nanokomposit Abu Sekam Padi Sebagai Filler Termoplastik Hdpe, Jurnal Einsten Prodi Fisika FMIPA Unimed, 4 (2) : 42-46.

*Corresponding author: p-ISSN : I2338 - 1981

E-mail : marthapadang94@gmail.com e-ISSN : $2407-747 \mathrm{x}$ 


\section{PENDAHULUAN}

Ilmu rekayasa material menjadi suatu kajian yang sangat diminati akhir akhir ini. Pemanfaatan material yang lebih dikembangkan saat ini adalah polimer. Plastik merupakan salah satu bahan yang paling umum kita lihat dan gunakan. Plastik adalah suatu polimer yang mempunyai sifat-sifat unik dan luar biasa.Bahan plastik secara bertahap mulai menggantikan gelas, kayu dan logam. Hal ini disebabkan bahan plastik mempunyai beberapa keunggulan, yaitu: ringan, kuat, mudah dibentuk, anti karat, tahan terhadap bahan kimia, mempunyai sifat isolasi listrik yang tinggi, dapat dibuat berwarna maupun transparan dan biaya proses yang lebih murah.

HDPE memiliki kekuatan tarik dan gaya antar molekul yang tinggi, bersifat lebih keras dan bisa bertahan pada temperatur tinggi $\left(120{ }^{\circ} \mathrm{C}\right)$, dan memiliki aplikasi yang luas, walaupun mempunyai kelebihan HDPE merupakan plastik yang terbuat dari minyak bumi dan juga merupakan plastik yang sangat sulit terdegradasi (Wikipedia, 2013). Salah satu cara untuk membuat polimer sintetik seperti polietilen dapat terdegradasi adalah dengan membuatnya menjadi suatu komposit polimer dengan polietilen jenis high density polyethylene (HDPE) sebagai matriks dan polimer alam sebagai filler yang berfungsi untuk meningkatkan sifat fisik material dan untuk mengurangi biaya komponen, mempercepat proses pencetakan dan meningkatkan konduktivitas termal polimer serta untuk meningkatkan kepadatan dan kekuatan polimer, meningkatkan modulus dan kekerasan polimer (Xanthos, 2005).

Produksi padi menghasilkan limbah yang disebut dengan sekam. Abu sekam padi mengandung kadar silika cukup tinggi (87-97\%). Mengingat tingginya kandungan silika dalam abu sekam padi maka dilakukan suatu upaya untuk memanfaatkan abu sekam padi sebagai bahan dalam pembuatan nano material $\mathrm{SiO}_{2}$ yang akan digunakan sebagai bahan pengisi (filler) pembuatan nano komposit (Kalaphaty, et al. 2000).

PEG 6000 dipakai untuk membentuk dan mengontrol ukuran dan struktur pori. 6000 menyatakan berat molekul dengan meningkatnya berat molekul dari PEG ini dapat meningkatkan tingkat kelarutannya dalam air. Dimana daya hambat terhadap pembentukan kristal stabil lebih tinggi, higroskopisnya yang lebih baik, suhu beku, berat jenis, suhu nyala, kekentalan dan tekanan uap juga lebih baik Dalam hal ini PEG berfungsi sebagai template, dan juga pembungkus partikel sehingga tidak terbentuk agregat, hal ini dikarenakan PEG terjebak pada permukaan partikel dan menutupi ion positif partikel, dan pada akhirnya akan diperoleh hasil partikel dengan bentuk bulatan yang seragam sehingga tidak terjadi penggumpalan (Wahyuni, dkk. 2014). Penelitian mengenai pencampuran HDPE dengan filler abu sekam padi, PEg-MA sebagai kompatibiliser. Untuk mengetahui analisis struktur morfologinya menggunakan scanning electron microscopy (SEM) dan pengujian sifat mekanis dilakukan uji tarik nanokomposit Abu Sekam Padi/HDPE.

\section{METODELOGI PENELITIAN Lokasi, Bahan dan Alat Penelitian}

Penelitian ini untuk persiapan sampel dilakukan di Laboratorium Kimia Fakultas Matematika dan Ilmu Pengetahuan Alam Universitas Negeri Medan. Untuk pembuatan Nanokomposit dan pengujian akan dilakukan di Pusat Penelitian Fisika Lembaga Ilmu Pengetahuan Indonesia ( LIPI) Bandung mulai Februari - April 2016.

Bahan yang digunakan dalam penelitian ini adalah abu sekam padi, Termoplastik HDPE diproduksi pt titan petrokimia nusantara, Aquades, Pe-g-ma produksi sigma aldrich USA, $\mathrm{HCl} 2 \mathrm{M}$, $\mathrm{NaOH}$ 2,5M, PEG 6000.

Alat yang digunakan dalam penelitian ini adalah magnetic stirrer, Timbangan digital, Ayakan 200 mesh, .Oven, SEM, Ballmill, Mechanical 
Eva Marlina Ginting dan Martha Marchofinece Padang, Analisis Sifat Mekanis Dan Struktur Nanokomposit Abu Sekam Padi Sebagai Filler Termoplastik Hdpe

Testing, Dumbel hot press, Internal Mixer, XRD.

\section{Preparasi Nanopartikel Abu Sekam Padi}

Adapun nanopartikel abu sekam padi yang telah dihasilkan dari proses sintesis dengan perbandingan 1:3 dengan PEG 6000 dengan metode kopresipitasi, kemudian dikeringkan hingga benarbenar-benar kering. Dan kemudian di ballmill/digerus selama kurang lebih 6 jam untuk menghasilkan nanopartikel dengan ukuran yang lebih baik.

Pembuatan Nanokomposit

Tabel 1. Komposisi Campuran Bahan Nanokomposit dalam Internal Mixer

\begin{tabular}{|c|c|c|c|c|c|c|}
\hline \multirow{2}{*}{ Bahan } & \multicolumn{6}{|c|}{$\begin{array}{c}\text { Komposisi Campuran } \\
\text { (\%) berat }\end{array}$} \\
\cline { 2 - 7 } & S0 & S1 & S2 & S3 & S4 & S5 \\
\hline $\begin{array}{c}\text { Termoplastik } \\
\text { HDPE }\end{array}$ & 100 & 96 & 94 & 92 & 90 & 88 \\
\hline Pe-g-MA & 0 & 2 & 2 & 2 & 2 & 2 \\
\hline $\begin{array}{c}\text { Nanopartikel } \\
\text { abu sekam padi }\end{array}$ & 0 & 2 & 4 & 6 & 8 & 10 \\
\hline
\end{tabular}

Pembuatan Nanokomposit
dilakukan dengan mencampurkan termoplastik HDPE dengan Nanopartikel menggunakan internal mixer laboplastomil dengan volume chamber 60 cc dengan persentasi pengisian $70 \%$ setara dengan 60 gr. Suhu campuran pada $150^{\circ} \mathrm{C}$ dengan kecepatan rotor 60 rpm selama 10 menit dan spesimen menurut standar JIS K 6781.

\section{HASIL DAN PEMBAHASAN}

Berdasarkan karakterisasi yang dilakukan dengan mesin uji mekanis diperoleh data kekuatan tarik, regangan putus, tegangan putus, dan modulus Young's Seperti diperlihatkan pada tabel berikut.

Tabel 2. Data Hasil Pengujian Sifat Mekanis Nanokomposit

\begin{tabular}{|c|c|c|c|c|}
\hline Material & $\begin{array}{l}\text { Kekuat } \\
\text { an } \\
\text { Tarik } \\
(\mathrm{MPa})\end{array}$ & $\begin{array}{l}\text { Modulus } \\
\text { Young's } \\
\text { (MPa) }\end{array}$ & $\begin{array}{l}\text { Tegangan } \\
\text { Putus } \\
(\mathrm{MPa})\end{array}$ & $\begin{array}{l}\text { Regang } \\
\text { an } \\
\text { Putus } \\
\text { (\% GL) }\end{array}$ \\
\hline $\begin{array}{l}\text { HDPE } 100 \\
\% \text { (S0) } \\
\text { HDPE/Pe- } \\
\text { g-MA/Nano }\end{array}$ & 22.59 & 423.58 & 14.113 & 346.7 \\
\hline $\begin{array}{l}\mathrm{ASP} \\
\text { (S1) } \\
\mathrm{HDPE} / \mathrm{Pe}^{-} \\
\text {g-MA/Nano }\end{array}$ & 20.6 & 537.56 & 15.35 & 582.28 \\
\hline $\begin{array}{l}\text { ASP } \\
\text { (S2) } \\
\text { HDPE/Pe- } \\
\text { g-MA/Nano }\end{array}$ & 19.66 & 573.83 & 15.73 & 550.89 \\
\hline $\begin{array}{l}\text { ASP } \quad 6 \% \\
\text { (S3) } \\
\text { HDPE/Pe- } \\
\text { g-MA/Nano }\end{array}$ & 19.61 & 599.25 & 13.98 & 395.62 \\
\hline $\begin{array}{l}\text { ASP } \\
\text { (S4) } \\
\text { HDPE/Pe- } \\
\text { g-MA/Nano }\end{array}$ & 19.36 & 580.11 & 15.52 & 591.53 \\
\hline $\begin{array}{ll}\text { ASP } & 10 \% \\
(\mathrm{~S} 5) & \end{array}$ & 19.57 & 619.76 & 14.36 & 475.75 \\
\hline
\end{tabular}

Dari hasil uji tarik, nanokomposit HDPE/Abu Sekam Padi dengan menggunakan kompatibiliser Pe-g-MA dapat ditampilkan dalam bentuk grafik dengan menggunakan pengolahan data Microsoft excel. Untuk masing-masing kekuatan tarik dengan membandingkan hubungan antara komposisi \% berat Nanopartikel Abu Sekam Padi sebagai bahan pengisi (filler).

1. Kekuatan tarik

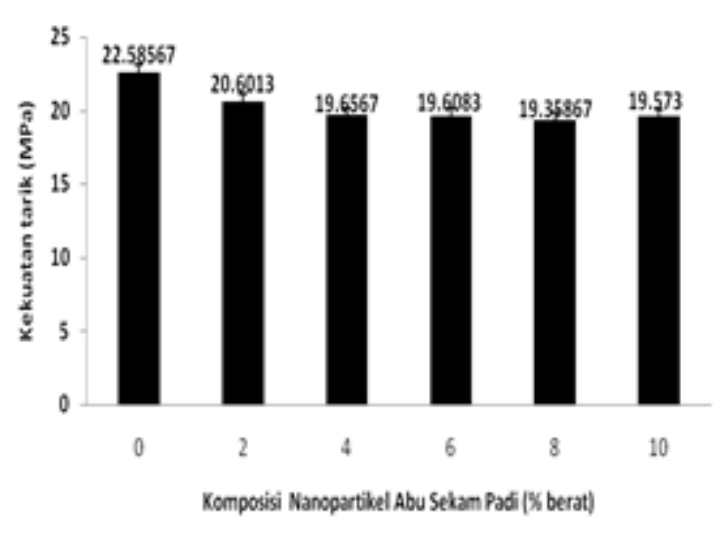

Gambar 1. Hubungan Kekuatan Tarik Terhadap Komposisi Nanopartikel ASP 


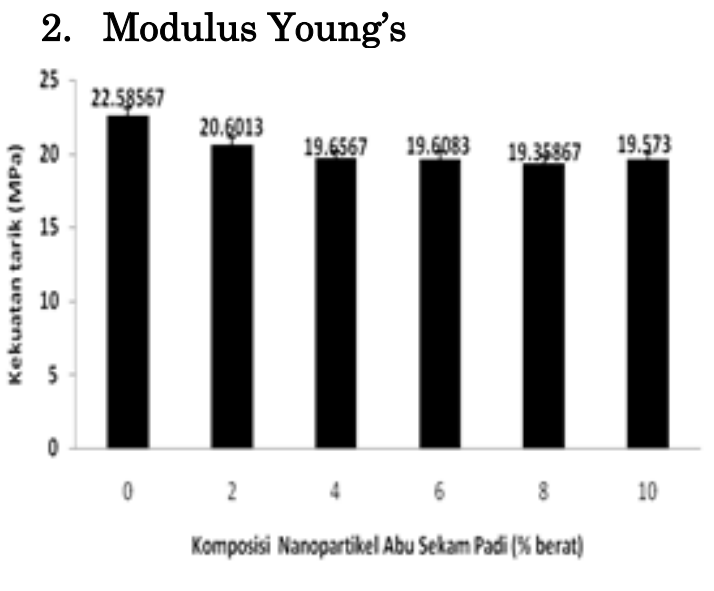

Gambar 2. Hubungan Modulus Young's Terhadap Komposisi Nanopartikel ASP

3. Tegangan Putus

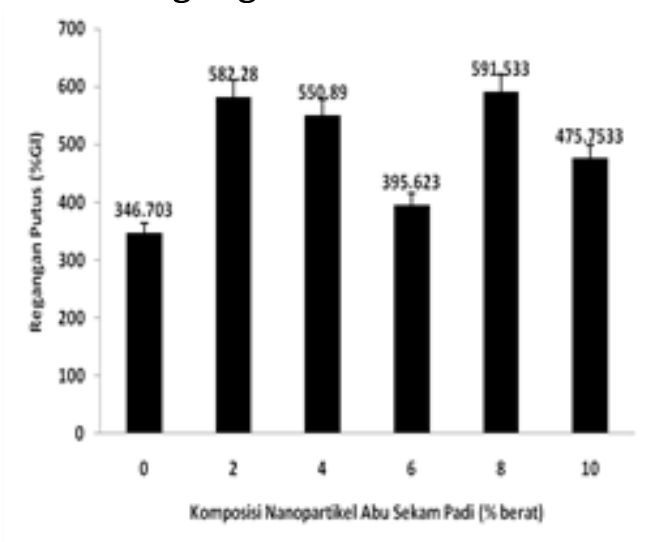

Gambar 3. Hubungan Tegangan Putus Terhadap Komposisi Nanopartikel ASP

\section{Regangan Putus}

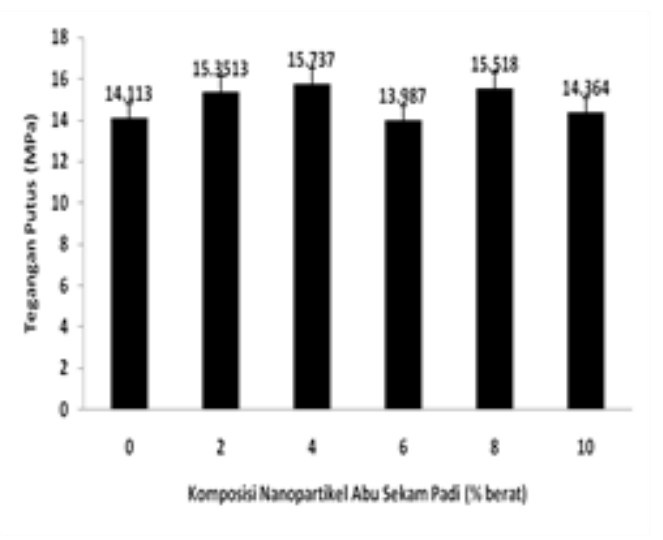

Gambar 4. Hubungan Regangan Putus Terhadap Komposisi Nanopartikel ASP

Dari data sifat mekanis pada kekuatan tarik untuk masing-masing sampel diperoleh bahwa sampel dengan nilai kekuatan tarik terbesar adalah pada sampel pertama (S1) sebesar 20.60133 $\mathrm{MPa}$ dengan komposisi kompositnya (98 \%) dan kompatibiliser Pe-g-MA konstan sebanyak $2 \%$ berat. Namun hasil ini masih berada dibawah kekuatan tarik HDPE murni yang memiliki kekuatan tarik sebesar 22.58567 MPa. Sedangkan untuk modulus Young's terjadi peningkatan dengan bertambahnya nanopartikel abu sekam padi dan yang terbesar adalah sampel yang ke lima (S5) dengan komposisi kompositnya adalah (88\%, 2\%, 10\%) dengan Modulus Young sebesar $619.7633 \mathrm{MPa}$ dan melampaui nilai Modulus Young's HDPE murni sebesar 423.58 MPa.

Begitu juga hasil untuk tegangan putus, dimana sampel dengan tegangan putus terbesar adalah sampel S2 komposisi nanokomposit $(94 \%, 4 \%)$ dan Pe-g-MA sebagai kompatibiliser tetap sebanyak $2 \%$. Adapun nilai tegangan putusnya sebesar $15.737 \mathrm{MPa}$ melampaui nilai tegangan putus HDPE murni yakni sebesar $14.113 \mathrm{MPa}$ dan untuk regangan putus sampel ke empat S4 memperoleh nilai regangan putus terbesar yakni 591.5333 \% GL dan juga melampaui nilai regangan putus HDPE murni yakni sebesar $346.7033 \%$ GL

Berdasarkan hasil pengujian mekanis (kekuatan tarik, modulus Young's, regangan putus dan tegangan putus) diketahui bahwa adanya peningkatan sifat mekanis nanokomposit HDPE dengan filler abu sekam padi, pertambahan nilai sifat mekanis yang meliputi modulus Young's, tegangan putus dan regangan putus sedangkan terjadi penurunan kekuatan tarik dibandingkan dengan HDPE murni.

\section{KESIMPULAN}

1. Hasil Uji tarik nanokomposit menghasilkan sampel dengan nilai terbaik beserta \% berat komposisi pengisi yang masing-masing untuk HDPE/Pe-g-MA/Nanopartikel Abu Sekam Padi dengan kekuatan tarik $20.60133 \mathrm{MPa}$ (pengisi 2\% berat), 
modulus Young's sebesar 619.7633 $\mathrm{MPa}$ (pengisi $10 \%$ berat), tegangan putus sebesar $15.737 \mathrm{MPa}$ (pengisi 4 $\%$ berat), dan regangan putus sebesar $591.5333 \%$ GL (pengisi 8 \% berat).

2. Penambahan PEG 6000 pada nanopartikel abu sekam padi yang digunakan sebagai filler nanokomposit abu sekam padi menurunkan kekuatan tarik tetapi menaikkan modulus Young's, regangan putus dan tegangan putus pada sifat mekanis nanokomposit HDPE/PE-g-MA/ASP.

\section{SARAN}

1. Sampel nanopartikel abu sekam padi setelah berhasil disintesis sebaiknya dikeringkan sampai benar-benar kering sehingga tidak terjadi penggumpalan sebelum diballmill atau digerus kemudian.

2. Penggunaan sampel sebaiknya lebih banyak lagi untuk variasi antara bahan pengisi (nanopartikel abu sekam padi) dan HDPE untuk menemukan hubungan erat antara keduanya didalam nanokomposit.

\section{DAFTAR PUSTAKA}

Akay, M., (2012), Introduction to Polymer Science and Technology, Ventus Publishing ApS, Irlandia Kalapathy, U., A. Proctor, dan J. Shultz. (2000). A Simple Method For Production Of Pure Silica From Rice Hull Ash. Biores. Tech. 73: 257-262

Dominic, M., Begum, P. M. S., Joseph, R., dan Jose, A. R., (2014), Rice Husk Silica- efficient Bio Filler in High Density Polyethylene, International Journal of Advanced Scientific and Technical Research 2(4) : 561-569 ISSN 2249-9954.

Islam , M. M., Kabir, H., Gafur, M. A., Bhuiyan, M. M. R., Kabir, M. A., Quadir, M. R., Ahmed, F., (2015), Study on Physio-Mechanical Properties of Rice Husk Ash Polyester Resin Composite,
International Letters of Chemistry, Physics and Astronomy $53: 95-105$.

Kalapathy, U., A. Proctor, dan J. Shultz. (2000). A Simple Method For Production Of Pure Silica From Rice Hull Ash. Biores. Tech. 73: 257-262.

Kord, B., (2011), Nanofiller Reinforcement Effects on The Thermal, Dynamic Mechanical, and Morphological Behavior of HDPE/Rice Husk Flour Composites, BioResources 6(2) : 1351-1358.

Xanthos, M., (2005), Fungsional Fillers for Plastics, Wiley \&Son , New York

Wahyuni , R., Halim, A., dan Febronica, S., (2014), Studi Sistem Dispersi Padat Karbamazepin Menggunakan Campuran Polimer Peg 6000 dan HPMC dengan Metoda Pelarutan. "Perkembangan Terkini Sains Farmasi dan Klinik IV" tahun 2014. 2014:233-240 
Jurnal Einstein 4 (2) (2016): 42-46 
Eva Marlina Ginting dan Martha Marchofinece Padang, Analisis Sifat Mekanis Dan Struktur Nanokomposit Abu Sekam Padi Sebagai Filler Termoplastik Hdpe 